\title{
EDDY-CURRENT TESTING OF THE STRUCTURE, HARDNESS AND ABRASIVE WEAR RESISTANCE OF LASER-HARDENED AND SUBSEQUENTLY TEMPERED HIGH-STRENGTH CAST IRON
}

\author{
A. V. Makarov ${ }^{1,2}$, E. S. Gorkunov ${ }^{1}$, L. Kh. $\operatorname{Kogan}^{2}$, I. Yu. Malygina ${ }^{1}$, A. L. Osintseva ${ }^{1}$ \\ ${ }^{I}$ Institute of Engineering Science, Ural Branch of the Russian Academy of Sciences, 34 Komsomolskaya st., \\ Ekaterinburg, Russian Federation; \\ ${ }^{2}$ M.N. Miheev Institute of Metal Physics, Ural Branch of the Russian Academy of Sciences, 18 Kovalevskoy st., \\ Ekaterinburg, Russian Federation
}

*Corresponding author. E-mail: labkm@imach.uran.ru; address for correspondence: ul. Komsomolskaya, Ekaterinburg, Russian Federation. Tel.: +7 (343) 375-35-78; fax: +7 (343) 374-53-30

Features of eddy-current testing to control the structure, hardness and the abrasive wear resistance of high-strength cast iron (3.6 C, 2.15 Si, 1.4 Mn, 0.07 S, 0.06 P, base - Fe, mass. \%) subjected to hardening using continuous laser radiation are investigated. The distribution of hardness, retained austenite content, wear rate and indicated eddy-current values through hardened layer depth is analyzed. The changes in the reading of the eddy-current instrument depend mainly on changes in retained austenite content. The influence of tempering in the interval from $100{ }^{\circ} \mathrm{C}$ to $600{ }^{\circ} \mathrm{C}$ on characteristics of laser-hardened layer is investigated. The possibility of eddy-current testing of the abrasive wear resistance of laser-hardened high-strength cast iron in the interval from $100{ }^{\circ} \mathrm{C}$ to $600{ }^{\circ} \mathrm{C}$ is established.

Keywords: laser treatment, tempering, hardened layer thickness, structure, hardness, abrasive wear, eddy-current testing.

DOI: $10.17804 / 2410-9908.2015 .6 .090-103$

\section{References}

1. Vengrinovich V.L., Astapchik S.A., Babushkin V.B., Velichko O.A., Avramchenko P.F. Special Features of Nondestructive Inspection of the Structure of Laser Hardened Zones. Physics and chemistry of materials treatment, 1984, vol. 18, iss. 6, pp. 565-568.

2. Vengrinovich V.L., Yakunin V.P., Legotin S.D., Busko V.N. Testing the parameters of the laser-hardened layers of ferromagnetic materials by the Barkhausen effect method. Defektoskopiya, 1986, no 2, pp. 87-89. (In Russian).

3. Malyshev V.S., Mashkovich S.B., Lomaev G.V., Goruchkin A.I., Kutanov Yu.I. Inspection of Pulsed Laser Hardening of 30khra Steel by the Barkhausen Effect Method. The Soviet Journal of Nondestructive Testing, 1986, vol. 22, iss. 12, pp. 860-863.

4. Malko I.I., Zatsepin N.N., Maksimkov V.E. Eddy-current testing of laser-hardened layers on products made of steels Kh12M, 45, U10 and ShKh15. Defektoskopiya, 1989, no 1, pp. 95-96. (In Russian).

5. Morgner W., Reuter M. Prüfung lasergehärteter Oberflächen mit dem Wirtbelstromverfahren. Neue Hütte, 1989, vol. 34, iss. 6, pp. 213-214.

6. Schneider D., Brenner B. Zerstörungsfreie Bestimmung der Einhärtungstiefe des lasergehärteten Stahls X20Cr13 mit Ultraschall-Oberflächenwellen. Neue Hütte, 1989, vol. 34, iss. 10, pp. 374-378.

7. Gorkunov E.S., Somova V.M., Makarov A.V., Kogan L.Kh., Korshunov L.G. Magnetic and electromagnetic methods for evaluating the wear resistance of steel products. Defektoskopiya, 1989, no 1, pp. 95-96. (In Russian).

8. Makarov A.V., Gorkunov E.S., Kogan L.Kh., Kolobylin Yu.M., Korshunov L.G., Osintseva

A.L. Features of electromagnetic methods for evaluating the wear resistance of medium-carbon Makarov A. V. et al. / Eddy-current testing of the structure, hardness and abrasive wear resistance of laser-

hardened and subsequently tempered high-strength cast iron 
structural steel subjected to laser or bulk hardening and tempering. Russian Journal of Nondestructive Testing, 2006, vol.42, iss. 7, pp. 443-451. DOI: 10.1134/S1061830906070035.

9. Kuznetsov A.I., Rodionova S.S., Gorkunov E.S., Pasechnik A.L., Skvortsova E.V. Testing of the graphite shape and the metal base structure in cast-iron castings for various applications. Defektoskopiya, 1996, no 9, pp. 3-15. (In Russian).

10. Morozova V.M., Nichipuruk A.P., Gavrilova L.D., Somova V. M. Temperature dependences of the coercive force of gray and white iron. Defektoskopiya, 1993, iss. 12, pp. 23-24.

11. Gorkunov E.S., Kharlamov V.V., Kogan L.Kh., Zadvorkin S.M. Evaluating the wear in steel-steel and iron-iron friction pairs by the eddy-current method. Russian Journal of Nondestructive Testing, 2005, vol. 41, iss. 4, pp. 218-223. DOI: 10.1007/s11181-005-0153-2.

12. Grigoryants A. G., Safonov A. N. Metody poverkhnostnoi lasernoi obrabotki [Methods of Surface Laser Processing]. M., Vyssh. Shk. Publ., 1987, 191 p. (In Russian).

13. Mordike B.L., Bergmann H.W. Laser melting and surface alloying. Rapidly Solidified Metastable Materials: Proceedings of Symposium, Boston, N.Y., 1984, p. 45-64.

14. Makarov A.V., Malygina I.Yu., Osintseva A.L. The effect of laser processing on the structure, wear resistance and fatigue properties of high-strength cast iron. Fizika i khimiya obrabotki materialov, 2006, no 4, pp. 46-55. (In Russian).

15. Makarov A.V., Korshunov L.G., Osintseva A.L. The effect of tempering and frictional heating on the wear resistance of the laser-hardened U8 steel. Treniye $i$ iznos, 1991, vol. 12, no 5, pp. 870-878. (In Russian).

16. Gorkunov E.S., Kogan L.Kh., Baraz E.M., Korolev A.L. Cementation quality inspection in 12Kh2N4A steel articles by electromagnetic methods, Defektoskopiya, 1993, iss.12, pp. 3-12.

17. Mayorov V.S., Mayorov S.V. Solid laser hardening of iron parts. Metal Science and Heat Treatment, 2009, vol. 51, iss. 3-4, pp. 106-108. DOI: 10.1007/s11041-009-9125-9.

18. Burlachenko O.V., Tikhvinskaya A.Yu., Zelensky A.A. Hardening of high-strength cast iron by a YAG:Nd-laser beam. Fizika $i$ khimiya obrabotki materialov, 2009, no 3, pp.55-57. (In Russian).

19. Minakov V.N., Bloshanevich A.M., Rudyk N.D., Puchkova V.Yu., Khomenko G.E. The effect of laser processing on the properties of VCh40 cast iron. Uprochnyayushchiye tekhnologii $i$ pokrytiya, 2011, no. 10, pp. 12-14. (In Russian).

20. Safonov A.N. Structure and properties of the surface of iron-carbon alloys melted by laser radiation. Metal Science and Heat Treatment, 2009, vol. 41, iss. 1, pp. 7-11. DOI: 10.1007/BF02466262.

21. Yur'yev A.B., Chinokalov V.Ya., Efimov O.Yu., Simakov V.P., Shitik E.V. Effect of plasma surface treatment on the structure and hardness of spherulitic iron. Metal Science and Heat Treatment, 2006, vol. 48, iss. 5-6, pp. 264-267. DOI: 10.1007/s11041-006-0082-2.

22. Safonov E.N. Structure and hardness of cast iron after surface hardening. Metal Science and Heat Treatment, 2005, vol. 47, no 9-10, pp. 434-439. DOI: 10.1007/s11041-006-0007-0.

23. Zhuravlev V.I., Safonov E.N., Starikov V.V., Farber V.M., CheremnykhV.G., Potemkina T.G. Surface hardening of ductile cast iron by a transferred electric arc. Izvestiya vysshikh uchebnykh zavedeniy. Chernaya metallurgiya, 1996, no. 10, pp. 48-49. (In Russian).

24. Fernandez-Vicente A, Pellizzari M., Arias J.L. Feasibility of laser surface treatment of pearlitic and bainitic ductile irons for hot rolls. Journal of Materials Processing Technology, 2012, vol. 212, iss. 5, pp. 989-1002. DOI: 10.1016/j.jmatprotec.2011.11.013.

25. Slatter T., Taylor H., Lewis R., King P. The influence of laser hardening on wear in the valve and valve seat contact. Wear, 2009, vol. 267, iss. 5-8, pp. 797-806. DOI: 10.1016/j.wear.2009.01.040. 
26. Dyakin V.V., Sandovsky V.A. Teoriya i raschet nacladnykh vikhretokovykh preobrazovatelei [Theory and Calculation of Attached Eddy-Current Transducers]. M., Nauka Publ., 1981, 136 p. (In Russian).

27. Makarov A.V., Gorkunov E.S., Kogan L.Kh., Kolobylin Yu.M., Osintseva A.L. Eddycurrent and coercive-force testing of abrasion-resistant ball bearing steel ШX15 subjected to laser and bulk thermal processing. Russian Journal of Nondestructive Testing, 2006, vol. 42, iss. 10, pp. 639-647. DOI: 10.1134/S1061830906100019.

28. Makarov A.V., Gorkunov E.S., Kolobylin Yu.M., Kogan L.Kh., Korshunov L.G., Malygina I.Yu., Osintseva A.L. Eddy-current testing of the durability of laser-hardend carburized chromonickel steel and quality of laser hardening of drill bits. Russian Journal of Nondestructive Testing, 2009, vol. 45, iss.10, pp. 698-710. DOI: 10.1134/S1061830909100052.

29. Dorofeev A.L. Induktsionnaya strukturoskopiya [Induction Structuroscopy]. M., Energiya Publ., 1973. 177 p. (In Russian).

30. Belous M.V., Cherepnin V.T., Vasiliev M.A. Prevrashcheniya pri otpuske stali [Trasformations in Steel under Tempering]. M., Metallurgiya Publ., 1973, 232 p. (In Russian).

31. Makarov A.V., Kogan L.Kh., Gorkunov E.S., Korshunov L.G., Atangulova L.V. An estimate of the abrasive wear resistance of low-alloy instrument steels by magnetic and electromagnetic methods. Russian Journal of Nondestructive Testing, 1998, vol. 34, iss. 5, pp. 305-312.

32. Makarov A.V., Kogan L.Kh., Gorkunov E.S., , Kolobylin Yu.M. Eddy current testing of wear-resistance of surface-carbonized chromium-nickel 20KhN3A steel grade. Defektoskopiya, 2001, iss. 2, pp. 67-78.

33. Gorkunov E.S., Kogan L.Kh., Morozova V.M., Baraz E.M. Eddy current testing to thermal treatment of "thin sheet" articles made of carbon steel with deviation of carbon percentage. Defektoskopiya, 1993, iss. 3, pp. 62-66.

34. Makarov A.V., Korshunov L.G., Kogan L.Kh., Gorkunov E.S., Solodova I.L., Osintseva A.L. Abrasive wear resistance of carbon and low-alloy tool steels and its evaluation by the nondestructive methods. Treniye i iznos, 1998, vol. 19, no 5, pp. 633-641. (In Russian).

35. Gorkunov E.S., Makarov A.V., Kogan L.Kh. Magnetic and electromagnetic methods for testing the wear resistance of steel products. Kontrol. Diagnostika, 2000, no. 11, pp. 13-15. (In Russian). 
Подана в журнал: 30.11 .2015

УДК 620.179.14.662.223.662.09

DOI: $10.17804 / 2410-9908.2015 .6 .090-103$

\title{
ВИХРЕТОКОВЫЙ КОНТРОЛЬ СТРУКТУРНОГО СОСТОЯНИЯ, ТВЕРДОСТИ И АБРАЗИВНОЙ ИЗНОСОСТОЙКОСТИ ВЫСОКОПРОЧНОГО ЧУГУНА, ПОДВЕРГНУТОГО ЛАЗЕРНОЙ ЗАКАЛКЕ И ПОСЛЕДУЮЩЕМУ ОТПУСКУ
}

\author{
А. В. Макаров ${ }^{1,2}$, Э.С. Горкунов ${ }^{1}$, Л. Х. Коган ${ }^{2}$, И. Ю. Малыгина ${ }^{1 *}$, А. Л. Осинцева ${ }^{1}$ \\ ${ }^{I}$ Федеральное государственное бюджетное учреждение науки Институт машиноведения Уральского \\ отделения Российской академии наук, ул. Комсомольская, 34, Екатеринбург, Российская Федераиия \\ ${ }^{2}$ Федеральное государственное бюджетное учреждение науки Институт физики металлов имени \\ М.Н. Михеева Уральского отделения Российской академии наук, ул. С.Ковалевской, 18, 620990, \\ Екатеринбург, Российская Федерачия
}

*Ответственный автор. Электронная почта: labkm@imach.uran.ru; адрес для переписки: ул. Комсомольская, 34, Екатеринбург, Российская Федерация. Телефон: +7 (343) 375-35-78; факс: 374-53-30

Исследованы особенности применения вихретокового метода для контроля структурного состояния, твердости и абразивной износостойкости высокопрочного чугуна ВЧ 60-2 (3,6 C; 2,15 Si; 1,4 Mn; 0,07 S; 0,06 P; остальное - Fe, мас.\%), закаленного непрерывным излучением лазера. Изучено распределение по глубине упрочненного слоя твердости, содержания остаточного аустенита, интенсивности абразивного изнашивания и показаний вихретокового прибора. Показано, что изменения вихретоковых характеристик определяются, главным образом, изменением содержания остаточного аустенита. Изучено влияние отпуска в интервале температур $100-600{ }^{\circ} \mathrm{C}$ на характеристики закаленного лазером слоя. Установлено, что у чугуна ВЧ 60-2, подвергнутого лазерной закалке как с оплавлением поверхности, так и закаленного из твердого состояния, вихретоковым методом можно контролировать изменения абразивной износостойкости при отпуске в интервале температур $100-600{ }^{\circ} \mathrm{C}$.

Ключевые слова: лазерная обработка, отпуск, глубина упрочненного слоя, структура, твердость, абразивное изнашивание, вихретоковый контроль

\section{1. Введение}

Поиск эффективных путей неразрушающего контроля структурного состояния и прогнозирования физико-механических свойств поверхностных слоев железоуглеродистых сплавов, упрочненных современными методами высокоэнергетического воздействия, в частности лазерным излучением, представляет большой научный и практический интерес. Использование физических методов направлено, как правило, на контроль глубины упрочненного при лазерной обработке слоя [1-6]. Возможности применения электромагнитных методов для контроля износостойких структур, сформированных при лазерном воздействии на поверхности железоуглеродистых сплавов, обсуждаются значительно реже [7, 8]. Контроль чугунов производится прежде всего с целью определения формы графита, контроля твердости и определения наличия на поверхности серых чугунов отбеленных участков [9, 10]. Оценка величины износа пары трения чугун-чугун вихретоковым методом была проведена в работе [11].

В настоящем исследовании была поставлена задача применения вихретокового метода для контроля износостойкости структур, сформированных в поверхностном слое высокопрочного чугуна при лазерном воздействии по различным режимам.

Важен также вопрос контроля изменений структуры и свойств лазерноупрочненных поверхностей при отпуске (нагреве), так как изделия после лазерной закалки могут дополни-

Makarov A. V. et al. / Eddy-current testing of the structure, hardness and abrasive wear resistance of laser-

hardened and subsequently tempered high-strength cast iron 
тельно подвергаться отпуску с целью повышения их трещиностойкости, усталостной прочности и других прочностных характеристик [12-14]. Кроме того, значительный нагрев упрочненных лазером изделий может происходить при последующих технологических операциях (шлифование, сварка и др.), а также в условиях эксплуатации при повышенных температурах и в процессе трения (фрикционный нагрев) [15]. Поэтому в работе проводился анализ изменений при отпуске механических (твердости, износостойкости) и вихретоковых характеристик чугуна, подвергнутого лазерной закалке.

\section{2. Материал и методика}

Исследования выполняли на образцах высокопрочного чугуна ВЧ 60-2 химического состава (мас. \%): 3,60 C; 2,15 Si; 1,40 Mn; 0,07 S; 0,06 P; остальное Fe. Обработку непрерывным излучением $\mathrm{CO}_{2}$-лазера в режимах с оплавлением поверхности проводили на установке ЛТ1-2М в защитной атмосфере аргона при мощности излучения $\mathrm{P}=1,6-1,9$ кВт, скорости перемещения образцов под лучом $\mathrm{V}=66$ мм/мин. Луч на поверхности образцов имел форму прямоугольника длиной 8 и шириной 1,5-2,0 мм. Для увеличения поглощения лазерного излучения поверхность образцов обрабатывали 10-20 \%-ным раствором персульфата аммония при температуре $60^{\circ} \mathrm{C}$. Отпуск чугуна после лазерной обработки проводили при температуpax $100-600{ }^{\circ} \mathrm{C}$ в течение часа. Образцы для исследований размером $7 \times 7 \times 20$ мм вырезали из центральной части лазерной дорожки.

Испытания на абразивную износостойкость проводили при скольжении торцевых поверхностей образцов по закрепленному абразиву - шлифовальной шкурке марки 14A16 (электрокорунд зернистостью 160 мкм) со средней скоростью 0,175 м/с, при нагрузке $49 \mathrm{H}$, длине рабочего хода 100 мм, пути трения 18 м, поперечном смещении образца за один двойной ход 1,2 мм. Интенсивность абразивного изнашивания по глубине зон лазерного воздействия образцов чугуна ВЧ 60-2 определяли в процессе многократных испытаний, приводящих к последовательному удалению (изнашиванию) поверхностного слоя. Путь трения единичного испытания составлял 6,0 м. Для каждого отдельного испытания определяли интенсивность изнашивания по формуле $I h=Q / q S L$, где $Q$ - потери массы образца, г; $q$ - плотность

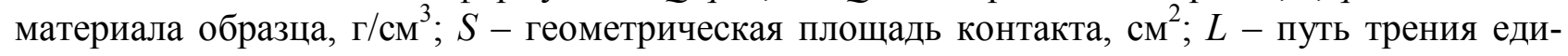
ничного испытания, см.

Твердость по методу Виккерса определяли на приборе ИТ 5010 при нагрузке 49 H, а микротвердость - на микротвердомере Leica VMHT AUTO при нагрузке 0,49 Н. Для структурных исследований использовали металлографический и рентгеновский методы анализа. Рентгеноструктурный анализ проводили на дифрактометре SHIMADZU в $\mathrm{CrK}_{\alpha}$-излучении. Определяли количество остаточного аустенита в металлической матрице оплавленного и закаленного из твердого состояния слоев.

Измерения электромагнитных параметров выполняли на лабораторном макете вихретокового прибора с использованием дифференциально включенных накладных трансформаторных преобразователей с сердечником броневого типа на частотах $f=72$ и 2,4 кГц [16]. Локальность использованных преобразователей позволяла проводить измерения на торцевых поверхностях образцов (7×7 мм) без влияния краевого эффекта. Измерения проводили также на серийно выпускаемом цифровом вихретоковом дефектоскопе «Вектор» с использованием дифференциального вихретокового преобразователя ВТ-4.03 (с сердечником из пермаллоя диаметром $\sim 3$ мм и внешним диаметром обмотки $\sim 12$ мм). Определяли величину фазового угла при частотах возбуждения преобразователя $\mathrm{f}=72$ и 90 кГц и усилении 36 дБ.

Makarov A. V. et al. / Eddy-current testing of the structure, hardness and abrasive wear resistance of laserhardened and subsequently tempered high-strength cast iron 
open-acCeEs journal

\section{3.Результаты и обсуждение}

Микроструктурные изменения, произошедшие в чугуне после лазерной обработки, представлены на рис. $1 a$. Исходная структура чугуна состоит из перлитной основы и частиц шаровидного графита, окаймленных ферритной оторочкой. Микротвердость неупрочненного чугуна составляет 280-360 HV 0,05. На поверхности образцов чугуна ВЧ 60-2 был сформирован упрочненный слой толщиной 1,3-2,2 мм при наличии оплавленного слоя толщиной 0,25-0,80 мм (рис. 1 б). Зона оплавления имеет мелкодендритное строение, а наличие включений графита зависит от режимов обработки $[13,17,18]$. Фазовый состав зоны оплавления включает мартенсит, аустенит и небольшое количество цементита. Аналогичный фазовый состав зоны переплава высокопрочного чугуна ВЧ 40 с лазерным упрочнением отмечен в работе [19].

В зоне закалки из твердого состояния на месте бывших перлитных колоний образуются мартенситно-аустенитные структуры. В ферритной оторочке происходит частичное растворение графитных частиц с образованием высокоуглеродистого аустенита и аустенитноцементитных структур ледебуритного типа (рис. 16,8 ). Ледебуритные структуры возникают при подплавлении металлической матрицы вокруг некоторых графитных включений в результате эффекта контактного плавления $[12,17,20]$. Микротвердость зоны закалки из твердого состояния зависит от режима лазерной обработки и достигает 7-9 ГПа.
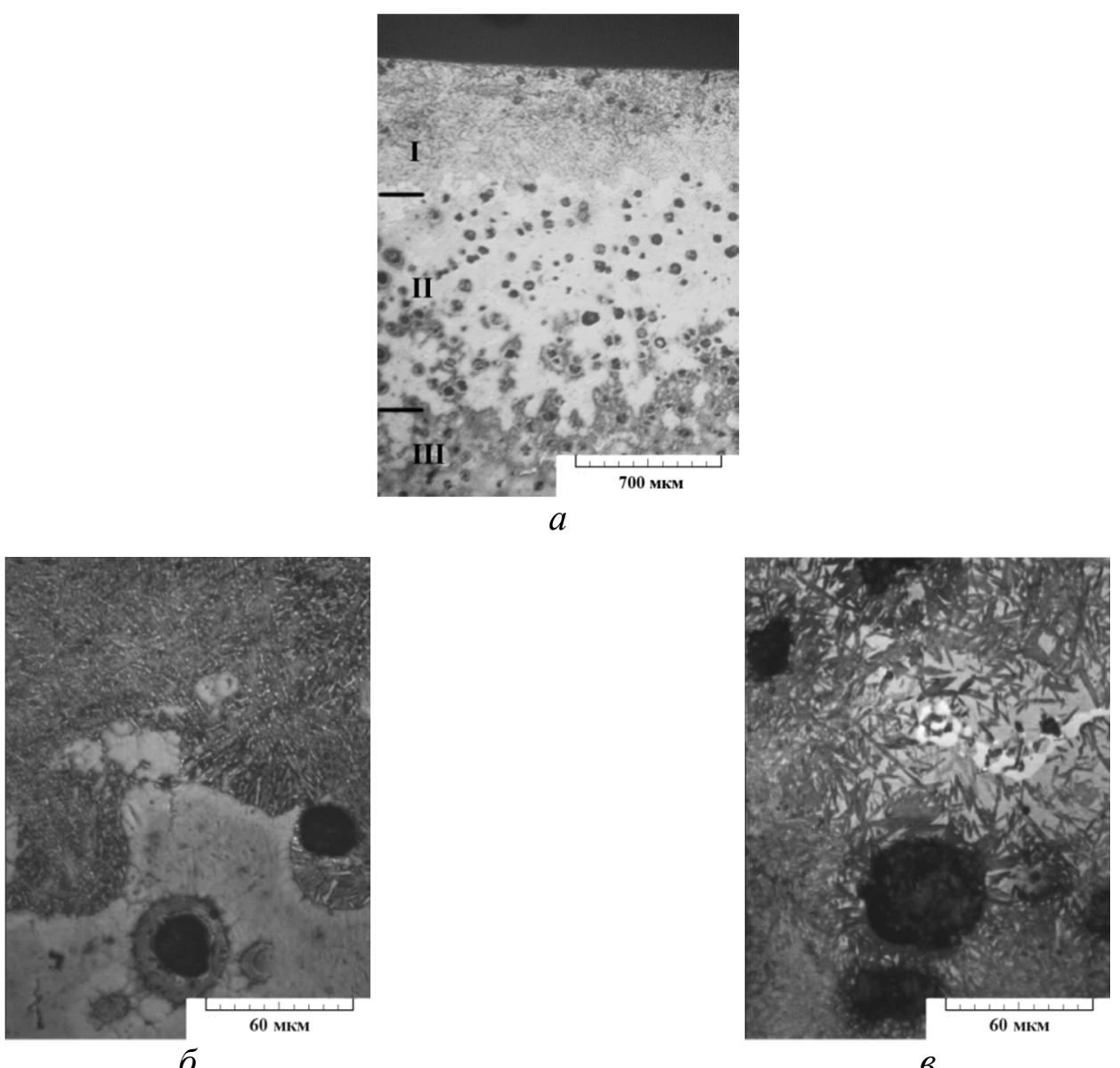

Рис. 1. Микроструктура чугуна ВЧ 60-2 после лазерной обработки с оплавлением: $a$ - общий вид зоны лазерного воздействия; $\sigma$ - граница зоны оплавления и зоны закалки из твердого состояния; 8 - зона закалки из твердого состояния: $I$ - зона оплавления; II - зона закалки из твердого состояния; III - основной металл

Makarov A. V. et al. / Eddy-current testing of the structure, hardness and abrasive wear resistance of laserhardened and subsequently tempered high-strength cast iron 
Рис. 2 представляет изменение твердости, количества остаточного аустенита, интенсивности абразивного изнашивания и показаний вихретокового прибора по глубине поверхностного слоя чугуна ВЧ 60-2, подвергнутого лазерной закалке с оплавлением на различную глубину. Оплавленный слой характеризуется высоким уровнем микротвердости: 800-1000 HV 0,05 для слоя меньшей глубины (рис. 2 a) и 700-1180 HV 0,05 для слоя большей глубины (рис. 2 б), твердость составляет 800 и 650 HV 5 соответственно. Содержание остаточного аустенита достигает 15-18 мас. \% в зоне с меньшей глубиной и 17-28 мас. \% в зоне с большей, что определяется большим временем пребывания металла при повышенных температурах, приводящим к более полному растворению графитных включений. Основной фазой является мартенсит. Присутствует также некоторое количество цементита, на что указывает наличие его линий на рентгенограммах. Аналогичная многофазная структура высокопрочных чугунов наблюдалась и при других видах поверхностной обработки в работах [21-24]. Такой фазовый состав и обеспечивает высокую твердость оплавленного слоя.

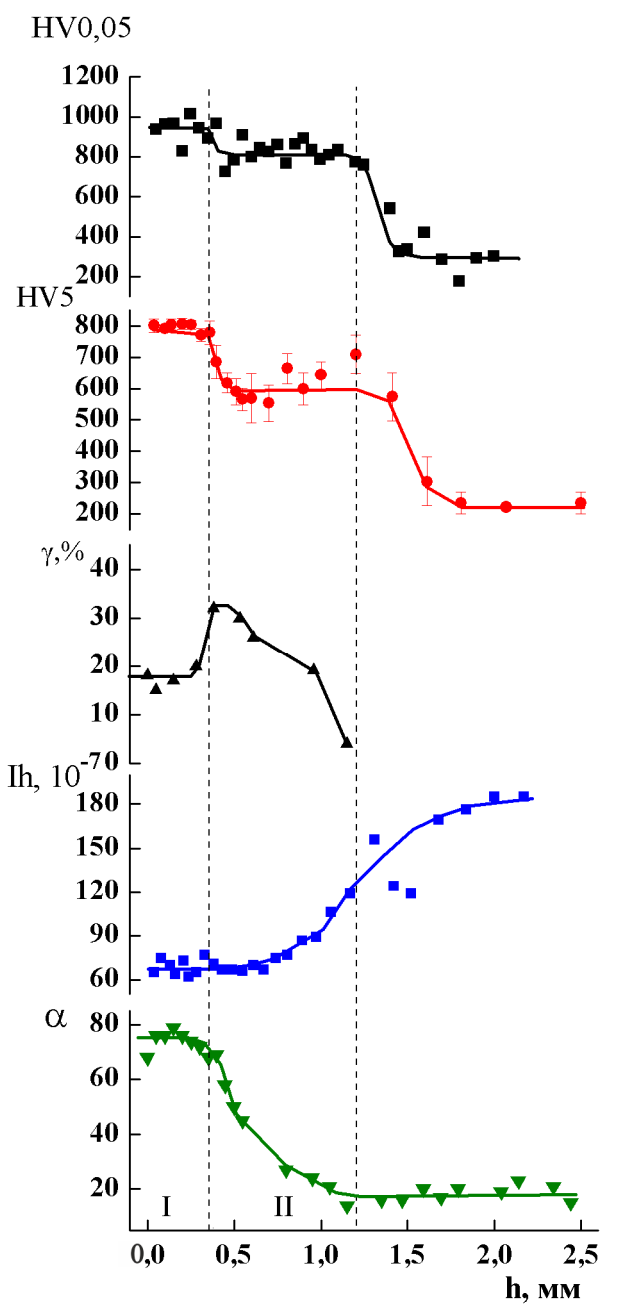

$a$

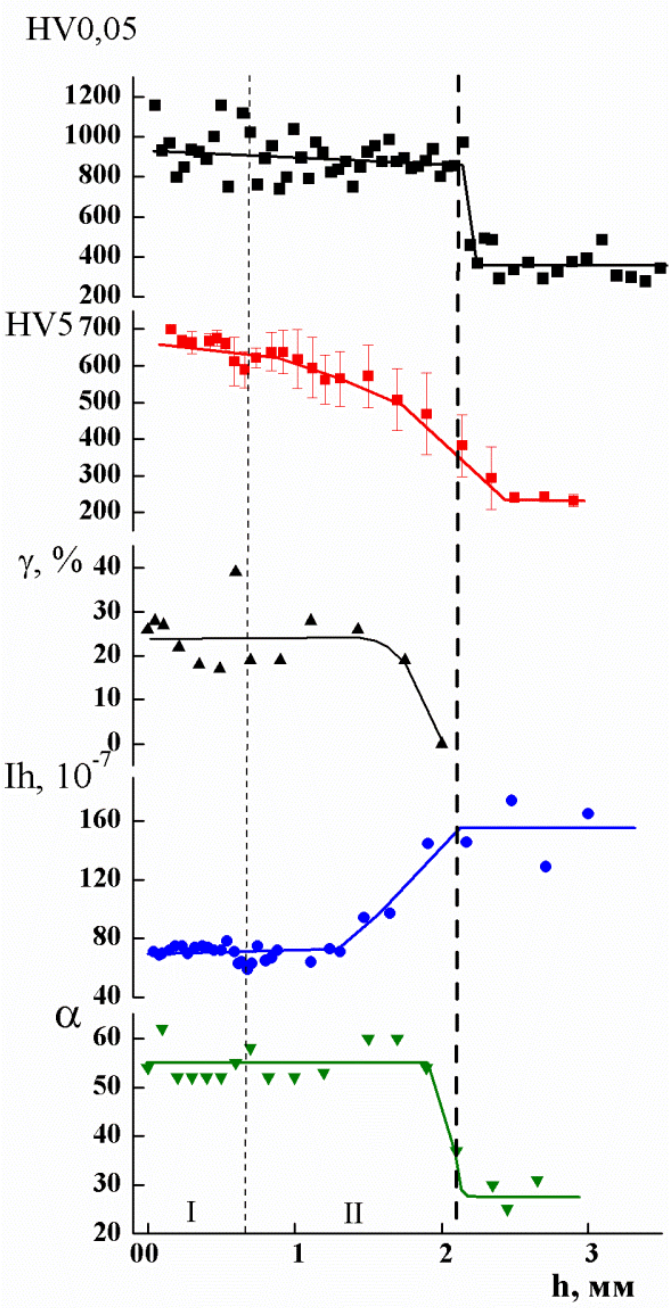

6

Рис. 2. Изменение микротвердости HV 0,05, твердости HV 5, содержания остаточного аустенита $\gamma$, интенсивности абразивного изнашивания Ih и показаний вихретокового прибора $\alpha$ по глубине $\mathrm{h}$ упрочненного лазером слоя чугуна ВЧ 60-2:

$a$ - обработка по режиму с меньшей глубиной упрочнения; $\sigma$ - обработка по режиму с большей глубиной упрочнения; $I$ - зона переплава; $I I$ - зона закалки из твердого состояния

Makarov A. V. et al. / Eddy-current testing of the structure, hardness and abrasive wear resistance of laserhardened and subsequently tempered high-strength cast iron 
Зона закалки из твердого состояния имеет меньшую микротвердость и твердость HV 5 по сравнению с оплавленным слоем (рис. $2 a$ ), что может быть связано с меньшим нагревом данного слоя. Для образцов с меньшей глубиной упрочненного слоя микротвердость и твердость HV 5 зоны закалки из твердого состояния остается постоянной по всей толщине. Вероятно, при выбранном режиме лазерной обработки скорость теплоотвода обеспечивает постоянную скорость охлаждения данного слоя, что приводит к формированию однородной структуры практически на всей глубине зоны закалки из твердого состояния. И только при приближении к основному металлу в соответствии с градиентом температуры формируется зона неполной закалки и наблюдается быстрое уменьшение твердости до уровня основного незакаленного металла. Количество остаточного аустенита при переходе от оплавленного слоя к закаленному из твердого состояния заметно повышается, а затем плавно снижается до 0 мас. \% при достижении исходного незакаленного металла. Повышение количества аустенита обусловлено более длительным нахождением при высоких температурах участков, граничащих с зоной переплава. Это делает возможным большее насыщение углеродом участков вокруг графитных частиц с образованием стабильного аустенита.

При большей глубине оплавленного слоя микротвердость отличается заметной неравномерностью (рис. 2 б). Это связано со значительным временем пребывания металла при высоких температурах. При этом в одних участках происходит всплытие графитных глобулей на поверхность и их выгорание, в других - растворение графитных включений с последующим образованием ледебурита. Большей неравномерностью в распределении микротвердости отличается и зона закалки из твердого состояния (рис. 2 б), особенно в зоне, приближенной к оплавленной. Наблюдается также более низкий средний уровень твердости HV 5, который плавно уменьшается при приближении к основному неупрочненному металлу, что обусловлено большим тепловложением при данном режиме обработки и, следовательно, меньшими скоростями охлаждения и более сильным развитием процессов самоотпуска, а также наличием более протяженной зоны неполной закалки.

Интенсивность абразивного изнашивания Ih зоны оплавления и зоны закалки из твердого состояния одинакова при обработке по обоим режимам и сохраняется на стабильном уровне практически по всей глубине упрочненного слоя (рис. 2). Изменение количества остаточного аустенита по глубине зоны лазерного воздействия и некоторое небольшое различие в твердости зон не оказывает заметного влияния на интенсивность изнашивания, так как уровень твердости абразива (2000 HV) значительно превышает твердость зоны лазерного воздействия. Плавное увеличение интенсивности изнашивания при приближении к основе обусловлено неравномерностью закаленного слоя по глубине и одновременным изнашиванием как закаленных участков, так и исходной неупрочненной структуры. Кроме того, при приближении к основе в структуре зоны лазерного воздействия наблюдаются закаленные мартенситные участки на месте перлитных зерен и участки феррита, не претерпевшие превращения, что также способствует росту интенсивности изнашивания. Износостойкость упрочненного слоя в 2-3 раза превышает износостойкость исходного чугуна, не подвергнутого лазерной обработке. Положительное влияние лазерной обработки на износостойкость чугунов в различных условиях испытаний отмечается многими исследователями. Повышение износостойкости высокопрочного чугуна ВЧ 40 после лазерной обработки с оплавлением поверхности в 3,8 раза установлено авторами работы [19]. Увеличение износостойкости седел клапанов двигателей, изготовленных из серого чугуна, показано в работе [25].

Рис. 2 свидетельствует также, что зоны лазерной закалки с оплавлением и без оплавления характеризуются показаниями вихретокового прибора $\alpha$, существенно отличающимися от показаний вихретокового прибора при исследованиях исходной структуры чугуна. Это свидетельствует о принципиальной возможности контролировать вихретоковым методом наличие на поверхности высокопрочного чугуна износостойкого слоя, сформированного при

Makarov A. V. et al. / Eddy-current testing of the structure, hardness and abrasive wear resistance of laserhardened and subsequently tempered high-strength cast iron 
лазерном воздействии. Изменение интенсивности сигнала вихретокового прибора в образцах, обработанных на различную глубину, происходит различным образом, и определяется, главным образом, изменением содержания остаточного аустенита по глубине упрочненной зоны. В образце с меньшей зоной лазерного воздействия, в котором содержание остаточного аустенита резко снижается по глубине зоны закалки из твердого состояния, наблюдается и непрерывное снижение вихретокового параметра $\alpha$ в данной зоне (рис. $2 a$ ). В образце с большой зоной лазерного воздействия, в котором остаточный аустенит сохраняется на высоком среднем уровне до значительной глубины, до этой же глубины остается неизменным и сигнал вихретокового прибора.

Показания вихретокового прибора $\alpha$ пропорциональны обобщенному вихретоковому параметру $\beta_{\mathrm{M}}$, который определяется значениями начальной магнитной проницаемости и удельного электросопротивления материала: $\alpha \sim \beta \sim \sqrt{ } 1 / \mu \cdot \rho$ [26]. Очевидно, снижение показаний $\alpha$ обусловлено преобладающим ростом начальной магнитной проницаемости чугуна по сравнению с уменьшением его электросопротивления при снижении количества остаточного аустенита в структуре. Определяющее влияние остаточного аустенита на изменение показаний вихретокового прибора $\alpha$ было ранее показано для стали ШХ15 [27] и цементированной стали 20ХНЗА после лазерной обработки [28]. Показания вихретокового прибора также зависят от глубины проникновения электромагнитного поля $\delta$, которая зависит от начальной магнитной проницаемости, удельного электросопротивления материала и частоты возбуждения преобразователя: $\delta=503 \sqrt{ } \rho / \mu \cdot f$ [29]. Для частоты возбуждения преобразователя 72 кГц, на которой проводились измерения, глубина проникновения электромагнитного поля составляла 0,21 мм. Это значительно меньше глубины зоны лазерного воздействия, которая для исследованных образцов составляла 1,2 мм (рис. 2 a) и 2,1 мм (рис. 2 б). Таким образом, влияние зоны неполной закалки и основного незакаленного металла на показания вихретокового прибора проявляется при удалении на значительную глубину от поверхности образцов. При переходе от зоны закалки из твердого состояния к основному металлу возникает протяженная переходная зона, в которой происходит постепенное снижение твердости, износостойкости и показаний вихретокового прибора.

На рис. 3 представлено изменение твердости, содержания остаточного аустенита, интенсивности абразивного изнашивания и вихретоковых характеристик оплавленного слоя и зоны закалки из твердого состояния при температурах отпуска 100-600 ${ }^{\circ} \mathrm{C}$. Отпуск при 100 ${ }^{\circ} \mathrm{C}$ вызывает некоторое снижение уровня микротвердости как оплавленного слоя, так и слоя, закаленного из твердого состояния, поскольку кремний, подобно другим элементам замещения, оказывает малое влияние на скорость протекания начальной стадии распада мартенсита [23]. Наблюдаемое при дальнейшем повышении температуры отпуска замедление разупрочнения обусловлено тормозящим влиянием кремния на процессы распада твердого раствора, возврата и рекристаллизации $\alpha$-фазы, на устойчивость $\varepsilon$-карбида и скорость коагуляции цементита [30]. Как видно на рис. $3 a$, остаточный аустенит в зоне лазерного оплавления чугуна обладает повышенной устойчивостью к распаду при нагреве до $300{ }^{\circ} \mathrm{C}$, что, по-видимому, также связано с наличием в $\gamma$-твердом растворе кремния. При данных температурах отпуска содержание остаточного аустенита сохраняется на уровне 35 мас. \%. При повышении температуры отпуска до $400{ }^{\circ} \mathrm{C}$ его содержание резко снижается до 15 мас. \%. Это количество аустенита сохраняется при дальнейшем повышении температуры отпуска вплоть до $600{ }^{\circ} \mathrm{C}$. Аустенит в зоне закалки из твердого состояния обладает меньшей устойчивостью (рис. 3 б). При отпуске в интервале температур $100-400{ }^{\circ} \mathrm{C}$ его количество постепенно уменьшается от 32 до 22 мас. \%. Нагрев при температурах 500-600 ${ }^{\circ} \mathrm{C}$ приводит к полному распаду аустенита в зоне закалки из твердого состояния.

Интенсивность изнашивания по корунду упрочненного лазером чугуна ВЧ 60-2 изменяется незначительно при температурах отпуска $100-500{ }^{\circ} \mathrm{C}$ для оплавленного слоя и

Makarov A. V. et al. / Eddy-current testing of the structure, hardness and abrasive wear resistance of laserhardened and subsequently tempered high-strength cast iron 
open-aCCeSS journal

$100-400{ }^{\circ} \mathrm{C}$ для слоя, закаленного из твердого состояния (см. рис. 3). Дальнейшее увеличение температуры отпуска до $600{ }^{\circ} \mathrm{C}$ вызывает существенное увеличение интенсивности изнашивания как оплавленного слоя, так и слоя, закаленного из твердого состояния, что объясняется значительным снижением их твердости. Сравнивая данные, полученные для чугуна ВЧ 60-2 с результатами, установленными ранее для сталей различного состава $[7,8,31-35]$, можно отметить следующие особенности, характерные для чугуна. У закаленных высокоуглеродистых сталей уже при нагреве до $100-125^{\circ} \mathrm{C}$ начинается заметное снижение износостойкости, обусловленное уменьшением концентрации углерода в высокоуглеродистом мартенсите и его способности к деформационному упрочнению при изнашивании. В результате отпуска при $250{ }^{\circ} \mathrm{C}$ по сравнению с закаленным состоянием у стали $45 \mathrm{X}$ износостойкость снижается в 1,5 раза при испытании по корунду. У закаленных и обработанных холодом высокоуглеродистых сталей У8 $(0,83 \% \mathrm{C})$ и ШХ15 $(1,00 \% \mathrm{C} ; 1,42 \% \mathrm{Cr})$ указанный отпуск снижает сопротивление изнашиванию корундом в 1,8 раза. Для чугуна ВЧ 60-2 отпуск при данной температуре снижает износостойкость всего в 1,15 раза. При повышении температуры отпуска выше $400{ }^{\circ} \mathrm{C}$ у сталей дальнейшее уменьшение износостойкости незначительно, тогда как у чугуна она снижается в 2 раза по сравнению с закаленным состоянием, так как именно в этом интервале температур происходит его значительное разупрочнение.
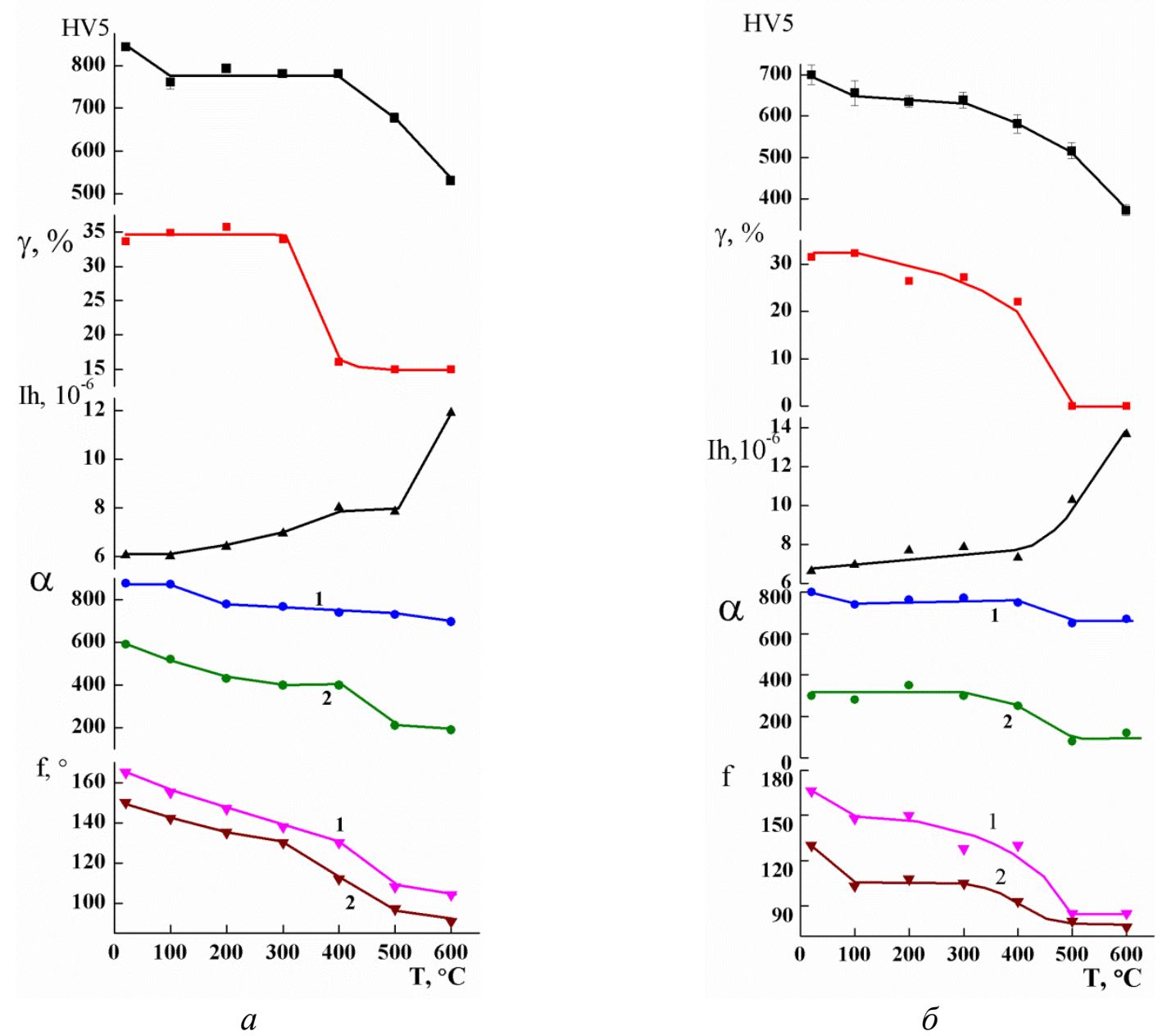

Рис. 3. Влияние температуры отпуска Т на твердость HV 5, содержание остаточного аустенита $\gamma$, интенсивность абразивного изнашивания Ih, показания вихретокового прибора $\alpha$ на частоте 2,4 кГц (1) и 72 кГц (2) и фазовый угол $\mathrm{f}$, измеренный вихретоковым прибором «Вектор» при усилении 36 дБ и частоте 72 кГц (1) и 90 кГц (2), чугуна ВЧ60-2, упрочненного лазером: $a$ - оплавленный слой; $\sigma$ - слой, закаленный из твердого состояния 
С ростом температуры отпуска до $600{ }^{\circ} \mathrm{C}$ для оплавленного слоя и до $500{ }^{\circ} \mathrm{C}$ для зоны закалки из твердого состояния наблюдается плавное снижение величины показаний вихретокового прибора $\alpha$ и фазового угла $\mathrm{f}$, измеренного с помощью вихретокового дефектоскопа «Вектор», в отличие от сталей, у которых изменение вихретокового параметра $\alpha$ происходит немонотонно [7]. Если в сталях изменение электромагнитных характеристик обусловлено распадом мартенсита, снижением дефектности и внутренних напряжений в $\alpha$-фазе, выделением и коагуляцией цементита, то в чугуне ВЧ 60-2 важное значение имеют процессы распада остаточного аустенита, содержание которого в исследуемых образцах достигает 30-35 мас. \%. Они в значительной мере определяют поведение вихретоковых характеристик при отпуске чугуна, подвергнутого лазерной закалке.

На рис. 4 представлены корреляционные зависимости между интенсивностью абразивного изнашивания при испытании по корунду и параметрами вихретокового контроля поверхности чугуна ВЧ 60-2, обработанной лазерным излучением.

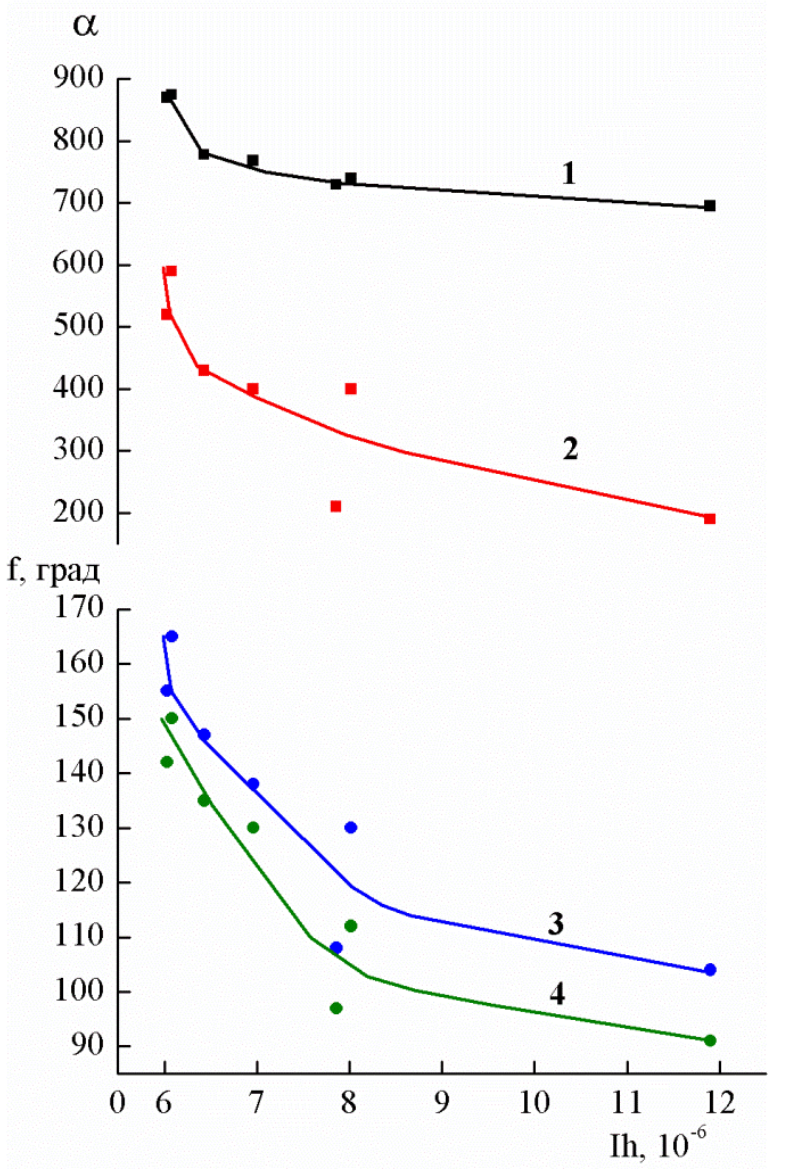

$a$

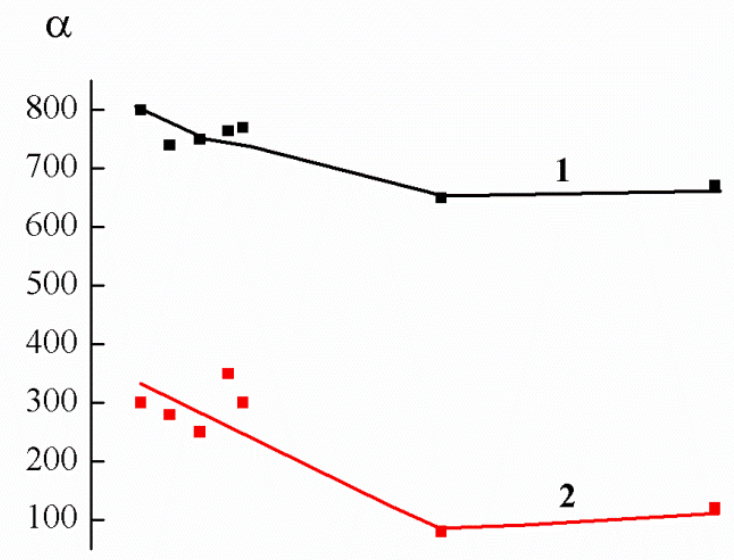

f, град

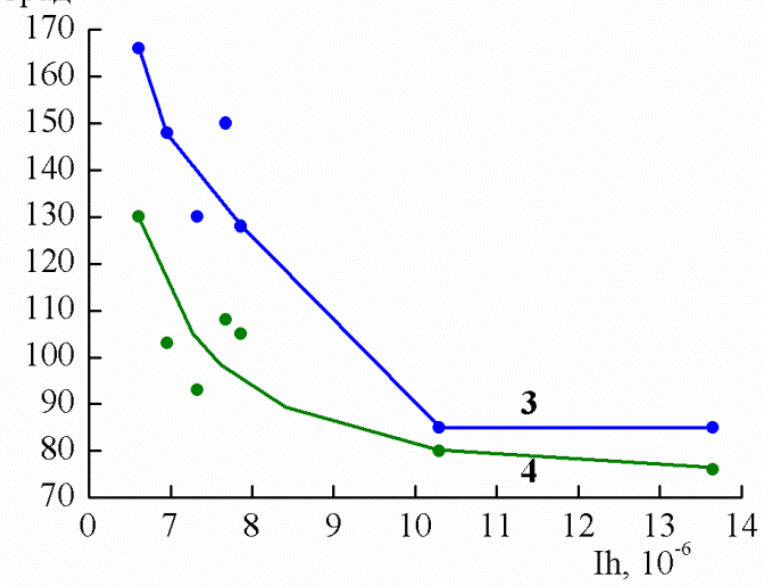

б

Рис. 4. Корреляционные зависимости между интенсивностью абразивного изнашивания Ih и показаниями вихретокового прибора $\alpha(1-2,4$ кГц; $2-72$ кГц) и фазовым углом вихретокового дефектоскопа «Вектор» $\mathrm{f}(3-72$ кГц; 4 - 90 кГц) чугуна ВЧ 60-2, подвергнутого лазерной закалке и отпуску: $a$ - оплавленный слой; $\sigma$ - слой, закаленный из твердого состояния

Можно видеть, что существует достаточно хорошая корреляция между показаниями вихретоковых приборов и интенсивностью абразивного изнашивания как для оплавленного слоя (рис. 4 a), так и для слоя, закаленного из твердого состояния (рис. 4 б). Наблюдается снижение показаний как лабораторного макета вихретокового прибора, так и серийного вих-

Makarov A. V. et al. / Eddy-current testing of the structure, hardness and abrasive wear resistance of laser-

hardened and subsequently tempered high-strength cast iron 
ретокового дефектоскопа «Вектор» при увеличении интенсивности абразивного изнашивания. Такая однозначная связь позволяет использовать вихретоковые приборы для контроля износостойкости закаленных лазером и отпущенных при температурах $100-600{ }^{\circ} \mathrm{C}$ изделий из высокопрочного чугуна ВЧ 60-2 во всем интервале температур отпуска.

\section{4. Заключение}

Установлено, что у чугуна ВЧ60-2 по всей глубине зоны лазерной закалки, включающей зону переплава и зону закалки из твердого состояния с аустенитно-мартенситной структурой, показания вихретокового прибора сохраняются на постоянном уровне, отличном от вихретоковых характеристик исходной структуры (перлит и графит с ферритной оторочкой). Это обусловливает возможность контроля вихретоковым методом наличия на поверхности чугуна ВЧ60-2 износостойких дорожек, сформированных при воздействии непрерывным излучением лазера.

Показано, что у чугуна ВЧ60-2, подвергнутого лазерной закалке как с оплавлением поверхности, так и закаленного из твердого состояния, вихретоковым методом можно контролировать изменения абразивной износостойкости при отпуске в интервале температур $100-600{ }^{\circ} \mathrm{C}$.

Вихретоковый контроль чугуна ВЧ60-2 можно осуществлять как на лабораторном макете вихретокового прибора, так и с помощью серийного вихретокового дефектоскопа «Вектор».

\section{Благодарность}

Работа выполнена в соответствии с планом Фундаментальных научных исследований Государственных академий наук на 2013-2020 годы по теме № 012013545989 и в рамках государственного задания ФАНО России (темы «Диагностика» № 01201463329 и «Структура» № 01201463331).

\section{Литература:}

1. Special Features of Nondestructive Inspection of the Structure of Laser Hardened Zones / V. L. Vengrinovich, S. A. Astapchik, V. B. Babushkin, O. A. Velichko, P. F. Avramchenko // Physics and chemistry of materials treatment. - 1984. - Vol. 18, iss. 6. - P. 565-568.

2. Контроль параметров лазерно-упрочненных слоев ферромагнитных материалов методом эффекта Баркгаузена / В. Л. Венгринович, В. П. Якунин, С. Д. Леготин, В. Н. Бусько // Дефектоскопия. - 1986. - № 2. - С. 87-89.

3. Inspection of Pulsed Laser Hardening of 30khra Steel by the Barkhausen Effect Method / V. S. Malyshev, S. B. Mashkovich, G. V. Lomaev, A. I. Goruchkin, Yu. I. Kutanov // The Soviet Journal of Nondestructive Testing. - 1986. - Vol. 22, iss. 12. - P. 860-863.

4. Малько И. И., Зацепин Н. Н., Максимков В. Е. Вихретоковый контроль глубины упрочненного после лазерной обработки слоя на изделиях из сталей Х12М, 45, У10, ШХ15 // Дефектоскопия. - 1989. - № 1. - С. 95-96.

5. Morgner W., Reuter M. Prüfung lasergehärteter Oberflächen mit dem Wirtbelstromverfahren // Neue Hütte. - 1989. - B. 34, H. 6. - S. 213-214.

6. Schneider D., Brenner B. Zerstörungsfreie Bestimmung der Einhärtungstiefe des lasergehärteten Stahls X20Cr13 mit Ultraschall-Oberflächenwellen // Neue Hütte. - 1989. - B. 34, H. 10. S. $374-378$.

7. Магнитные и электромагнитные методы оценки износостойкости стальных изделий / Э. С. Горкунов, В. М. Сомова, А. В. Макаров, Л. Х. Коган, Л. Г. Коршунов // Дефектоскопия. - 1995. - № 6. - C. 33-39.

Makarov A. V. et al. / Eddy-current testing of the structure, hardness and abrasive wear resistance of laser- 
8. Features of electromagnetic methods for evaluating the wear resistance of medium-carbon structural steel subjected to laser or bulk hardening and tempering / A. V. Makarov, E. S. Gorkunov, L. Kh. Kogan, Yu. M. Kolobylin, L. G. Korshunov, A. L. Osintseva // Russian Journal of Nondestructive Testing. - 2006. - Vol.42, iss. 7. - P. 443-451. - DOI: 10.1134/S1061830906070035.

9. Контроль формы графита и структуры металлической основы в отливках из чугунов различного назначения / А. И. Кузнецов, С. С. Родионова, Э. С. Горкунов, А. Л. Пасечник, Е. В. Скворцова // Дефектоскопия. - 1996. - № 9. - С. 3-15.

10. Temperature dependences of the coercive force of gray and white iron / V. M. Morozova, A. P. Nichipuruk, L. D. Gavrilova, V. M. Somova // Defektoskopiya. - 1993. - Iss. 12. - P. 23-24.

11. Evaluating the wear in steel-steel and iron-iron friction pairs by the eddy-current method / E. S. Gorkunov, V. V. Kharlamov, L. Kh. Kogan, S. M. Zadvorkin // Russian Journal of Nondestructive Testing. - 2005. - Vol. 41, iss. 4. - P. 218-223. - DOI: 10.1007/s11181-005-0153-2.

12. Григорьянц А. Г., Сафонов А. Н. Методы поверхностной лазерной обработки. - М. : Высшая школа, 1987. - $191 \mathrm{c.}$

13. Mordike B. L., Bergmann H. W. Laser melting and surface alloing // Rapidly Solidified Metastable Materials, Boston, Nov. 14-17 1983 : materials of symposium. - Boston, N.Y., 1984. P. 45-64.

14. Макаров А. В., Малыгина И. Ю., Осинцева А. Л. Влияние лазерной обработки на структуру, износостойкость и усталостные свойства высокопрочного чугуна // Физика и химия обработки материалов. - 2006. - № 4. - С. 46-55.

15. Макаров А. В., Коршунов Л. Г., Осинцева А. Л. Влияние отпуска и фрикционного нагрева на износостойкость стали У8, закаленной лазером // Трение и износ. - 1991. - Т. 12., № 5. - C. 870-878.

16. Cementation quality inspection in $12 \mathrm{Kh} 2 \mathrm{~N} 4 \mathrm{~A}$ steel articles by electromagnetic methods / E. S. Gorkunov, L. Kh. Kogan, E. M. Baraz, A. L Korolev // Defektoskopiya. - 1993. - Iss. 12. P. 3-12.

17. Mayorov V. S., Mayorov S. V. Solid laser hardening of iron parts // Metal Science and Heat Treatment. - 2009. - Vol. 51, iss. 3-4. - P. 106-108. - DOI: 10.1007/s11041-009-9125-9.

18. Бурлаченко О. В., Тихвинская А. Ю., Зеленский А. А. Упрочнение высокопрочного чугуна излучением YAG:Nd-лазера // Физика и химия обработки материалов. - 2009. - № 3. - С. 55-57.

19. Влияние лазерной обработки на свойства чугуна ВЧ40 / В. Н. Минаков, А. М. Блошаневич, Н. Д. Рудык, В. Ю. Пучкова, Г. Е. Хоменко // Упрочняющие технологии и покрытия. - 2011. - № 10. - С. 12-14.

20. Safonov A. N. Structure and properties of the surface of iron-carbon alloys melted by laser radiation // Metal Science and Heat Treatment. - 2009. - Vol. 41, iss. 1. - P. 7-11. DOI: $10.1007 / \mathrm{BF} 02466262$.

21. Effect of plasma surface treatment on the structure and hardness of spherulitic iron / A. B. Yur'yev, V. Ya. Chinokalov, O. Yu. Efimov, V. P. Simakov, E. V. Shitik // Metal Science and Heat Treatment. - 2006. - Vol. 48, iss. 5-6. - P. 264-267. - DOI: 10.1007/s11041-006-0082-2.

22. Safonov E. N. Structure and hardness of cast iron after surface hardening // Metal Science and Heat Treatment. - 2005. - Vol. 47, no 9-10. - P. 434-439. - DOI: 10.1007/s11041-006-0007-0.

23. Поверхностное упрочнение чугуна с шаровидным графитом электрической дугой прямого действия / В. И. Журавлев, Е. Н. Сафонов, В. В. Стариков, В. М. Фарбер, В. Г. Черемных, Т. Г. Потемкина // Известия высших учебных заведений. Черная металлургия. - 1996. - № 10. - С. 48-49.

24. Fernandez-Vicente A, Pellizzari M., Arias J. L. Feasibility of laser surface treatment of pearlitic and bainitic ductile irons for hot rolls // Journal of Materials Processing Technology. 2012. - Vol. 212. iss. 5. - P. 989-1002. - DOI: 10.1016/j.jmatprotec.2011.11.013.

Makarov A. V. et al. / Eddy-current testing of the structure, hardness and abrasive wear resistance of laser- 
25. The influence of laser hardening on wear in the valve and valve seat contact / T. Slatter, H. Taylor, R. Lewis, P. King // Wear. - 2009. - Vol. 267, iss. 5-8. - P. 797-806. DOI: 10.1016/j.wear.2009.01.040.

26. Дякин В. В., Сандовский В. А. Теория и расчет накладных вихретоковых преобразователей. - М. : Наука, 1981. - 136 с.

27. Eddy-current and coercive-force testing of abrasion-resistant ball bearing steel ШX15 subjected to laser and bulk thermal processing. Russian Journal of Nondestructive Testing / A. V. Makarov, E. S. Gorkunov, L. Kh. Kogan, Yu. M. Kolobylin, A. L. Osintseva. - 2006. Vol. 42, iss. 10. - P. 639-647. - DOI: 10.1134/S1061830906100019.

28. Eddy-current testing of the durability of laser-hardend carburized chromonickel steel and quality of laser hardening of drill bits / A. V. Makarov, E. S. Gorkunov, Yu. M. Kolobylin, L. Kh. Kogan, L. G. Korshunov, I. Yu. Malygina, A. L. Osintseva // Russian Journal of Nondestructive Testing. - 2009. - Vol. 45, iss.10. - P. 698-710. - DOI: 10.1134/S1061830909100052.

29. Дорофеев А. Л. Индукционная структуроскопия. - М. : Энергия, 1973. - 176 с.

30. Белоус М. В., Черепнин В. Т., Васильев М. А. Превращения при отпуске стали. - М. : Металлургия, 1973. - 232 с.

31. An estimate of the abrasive wear resistance of low-alloy instrument steels by magnetic and electromagnetic methods / A. V. Makarov, L. Kh. Kogan, E. S. Gorkunov, L. G. Korshunov, L. V. Atangulova // Russian Journal of Nondestructive Testing. - 1998. - Vol. 34, iss. 5. P. 305-312.

32. Eddy current testing of wear-resistance of surface-carbonized chromium-nickel 20KhN3 A steel grade / A. V. Makarov, L. Kh. Kogan, E. S. Gorkunov, Yu. M. Kolobylin // Defektoskopiya. 2001. - Iss. 2. - P. 67-78.

33. Eddy current testing to thermal treatment of "thin sheet" articles made of carbon steel with deviation of carbon percentage / E. S. Gorkunov, L. Kh. Kogan, V. M. Morozova, E. M. Baraz // Defektoskopiya. - 1993. - Iss. 3. - P. 62-66.

34. Абразивная износостойкость углеродистых и низколегированных инструментальных сталей и ее оценка неразрушающими методами / А. В. Макаров, Л. Г. Коршунов, Л. Х. Коган, Э. С. Горкунов, И. Л. Солодова, А. Л. Осинцева // Трение и износ. - 1998. - Т. 19, № 5. C. 633-641.

35. Горкунов Э. С., Макаров А. В., Коган Л. Х. Магнитные и электромагнитные методы контроля износостойкости стальных изделий // Контроль. Диагностика. - 2000. - № 11. C. $13-15$. 